\title{
The arcuate nucleus kisspeptin response to increased nutrition in rams
}

\author{
S.E. Rietema A, P.A.R. Hawken A, C.J. Scott ${ }^{B}$, \\ M.N. Lehman ${ }^{C}$, G.B. Martin ${ }^{\star A}$ and J. T. Smith ${ }^{\star D E}$ \\ A School of Agriculture and Environment, The University of Western Australia, Crawley, Western Australia, 6009, \\ Australia \\ B School of Biomedical Sciences, Charles Sturt University, Wagga Wagga, New South Wales, 2678, Australia \\ C Brain Health Research Institute and Department of Biological Sciences, Kent State University, PO Box 5190, \\ Kent, Ohio 44242-0001 USA \\ D The School of Human Sciences, The University of Western Australia, Crawley, Western Australia, 6009, \\ Australia \\ ECorresponding author. E-mail: jeremy.smith@uwa.edu.au \\ *Authorship note: Graeme B. Martin and Jeremy T. Smith contributed equally to this work.
}

\begin{abstract}
Rams respond to acute nutritional supplementation by increasing the frequency of GnRH pulses. Kisspeptin neurons may mediate the effect of environmental cues on GnRH secretion, so we tested whether the ram response to nutrition involves activation of kisspeptin neurons in the arcuate nucleus (ARC) - KNDy neurons. Rams were given extra lupin grain with their normal ration. Blood was sampled for prior to feeding, and continued until animals were killed for collection of brain tissue at 2 or $11 \mathrm{~h}$ post-supplementation. In supplemented rams, LH pulse frequency increased after feeding, whereas control animals showed no change. Within the caudal-ARC, there were more kisspeptin neurons in supplemented rams than in controls and a higher proportion of kisspeptin cells co-expressed Fos, regardless of time of euthanasia. There were more Fos cells in the mid-ARC and mid dorsomedial hypothalamus (DMH) of the supplemented rams compared to control rams. No effect of nutrition was found on kisspeptin expression in the rostral- or mid-ARC, or on GnRH expression in the pre-optic area (POA). Kisspeptin neurons in the caudal-ARC appear to mediate the increase in $\mathrm{GnRH} / \mathrm{LH}$ production due to acute nutritional supplementation, supporting the hypothesised role of the KNDy neurons as the pulse generator for GnRH.
\end{abstract}

\section{Introduction}

Successful reproduction relies on the pulsatile secretion of gonadotrophin releasing hormone (GnRH), with changes in the frequency of these pulses switching reproduction between active and inactive states. The secretion of GnRH pulses is regulated by an integration of neuronal inputs reflecting environmental factors, such as photoperiod and nutrient availability, and endogenous factors, such as sex steroid feedback (Tjondronegoro et al. 1996; Blache et al. 1997). In many species, the regulation of GnRH secretion in this way allows reproduction to be timed advantageously, for example switching on reproduction when sufficient nutrition is available to support the energy demands of reproduction and this response is more prominent in females where the investment in reproduction is high. Nevertheless, the male sheep responds to an acute increase in nutrition by increasing the frequency of GnRH pulses within 6 hours of feeding (Zhang et al. 2004; Zhang et al. 2005), leading to an increase in testosterone and sperm production (Blache et al. 2002; Guan and Martin 2017). However, the neuronal link between hypothalamic-pituitary-gonadal (HPG) activity and nutritional cues is not fully understood. It most likely involves insulin and leptin, two metabolic hormones that are known to affect reproduction (Blache et al. 2006). However, GnRH neurons lack receptors for both insulin and leptin, indicating that if the link exists, it must be at least "one step back" from the GnRH neurons (Clarke 2011). 
Kisspeptin is critically involved in HPG regulation, as kisspeptin administration stimulates GnRH activity, and kisspeptin antagonists inhibit it (Messager et al. 2005; Roseweir et al. 2009). In sheep, kisspeptin neurons are found in the arcuate nucleus (ARC) and preoptic area (POA) (Smith and Clarke 2007) and those in the former are known to co-express neurokinin B (NKB) and dynorphin (Dyn) (Goodman et al. 2007) with their requisite receptors (Navarro et al. 2009; Amstalden et al. 2010; Weems et al. 2016). These 'KNDy' neurons are proposed to act via a reciprocally interconnected network to drive GnRH pulsatility, with strong data in sheep (Lehman et al. 2010; Goodman et al. 2013; Li et al. 2015) and mice (Navarro et al. 2009; Clarkson et al. 2017).

Evidence further suggests that kisspeptin neurons may be the 'missing link' between HPG activity and nutritional cues. KNDy neurons are known to mediate environmental effects on reproduction they are involved in the 'ram effect', a phenomenon where ewes show a surge in HPG activity when presented with a novel ram (De Bond et al. 2013; Fabre-Nys et al. 2017). Importantly, kisspeptin also seems to be involved in responses to nutritional signals, particularly in rodents, where several lines of evidence have been published: i) fasting decreases Kiss mRNA and central administration of kisspeptin reverses fasting-induced inhibition of GnRH secretion (Castellano et al. 2005); ii) kisspeptin neurons apposite to GnRH neurons possess insulin, leptin and ghrelin receptors (Qiu et al. 2011; Cravo et al. 2013; Frazao et al. 2014; Qiu et al. 2015); iii) leptin-deficient $o b / o b$ mice have lower levels of Kiss $1 \mathrm{mRNA}$ in the ARC, compared to wild-type controls, and the peripheral administration of leptin reduces this effect (Smith et al. 2006); iv) kisspeptin also interacts with the insulin signalling pathway in the hypothalamus, as evidenced by diabetic rats having diminished expression of Kiss 1 mRNA, an effect that can be reversed with insulin therapy (Castellano et al. 2006); and v) impairment of kisspeptin signalling decreases metabolism and increases obesity and glucose intolerance (Tolson et al. 2014). Therefore, in this study, we tested whether kisspeptin is involved in the GnRH response to an acute increase in nutrition in sexually mature male sheep. We hypothesise that the stimulatory effect of a nutritional supplement on LH pulse frequency will be accompanied by activation of the KNDy cells.

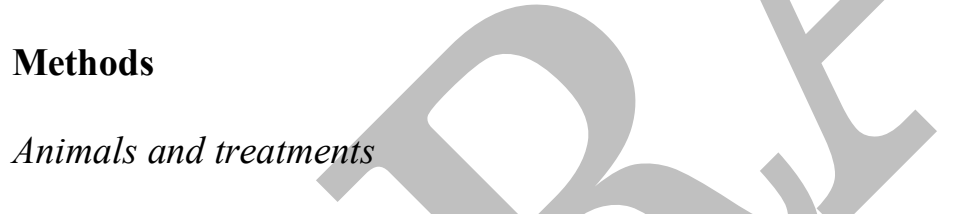

The experimental procedures were approved by the Animal Ethics Committee of the University of Western Australia, according to the recommendations of the National Health and Medical Research Council of Australia under RA/3/100/1311.

Sexually experienced male sheep ( 2 years old; Merino; $n=24$ ) were individually penned in indoor housing at the University of Western Australia $\left(31^{\prime} 58^{\circ} \mathrm{S}\right)$. The experiment was performed in May (southern hemisphere) and photoperiod approximated external conditions 12L: 12D with lights on at $6.30 \mathrm{am}$. Housing was kept at constant temperature $\left(20 \pm 2{ }^{\circ} \mathrm{C}\right)$ and relative humidity $(50 \pm 2 \%)$. Animals were acclimatised to housing and diet for a $2 \mathrm{wk}$ period prior to experimentation. Animals were fed a diet designed to maintain constant bodyweight and the daily allowance consisted of chaff, lupins and minerals, to yield $8.7 \mathrm{MJ}$ of metabolisable energy/KG. Animals were fed at a consistent time each day.

Rams were allocated into 2 groups, balanced for weight: control $(\mathrm{n}=8) 69.9 \pm 3.74 \mathrm{~kg} \mathrm{BW}$ and supplemented $(\mathrm{n}=16) 70.4 \pm 2.46 \mathrm{~kg}$ BW. Sampling was conducted over 2 days. Jugular cannulas were inserted into each animal the day prior to sampling. On each sampling day, blood was sampled every 20 min beginning $8 \mathrm{~h}$ prior to the regular feeding time. At feeding time animals were fed the regular ration (control group) or the regular ration plus a supplement of lupin grain ( $30 \mathrm{~g} / \mathrm{kg}$ body weight, supplemented group). Blood sampling continued until animals were killed and brains collected, at either $2 \mathrm{~h}$ (control $\mathrm{n}=5$, supplemented $\mathrm{n}=7$ ) or $11 \mathrm{~h}$ post-feeding (control $\mathrm{n}=3$, supplemented $n=9$ ). 
Animals were killed by an intravenous overdose of sodium pentobarbital (Lethabarb; Virbac, Peakhurst, NSW, Australia), then heads quickly removed, and brains perfused with $2 \mathrm{~L}$ of $0.9 \%$ saline and $3 \mathrm{~L}$ of $4 \%$ paraformaldehyde ( $\mathrm{pH} 7.4)$. Blocks of tissue containing the hypothalamus were dissected out and stored in $4 \%$ paraformaldehyde for a further $24 \mathrm{~h}\left(4^{\circ} \mathrm{C}\right)$ followed by $24-48 \mathrm{~h}$ in $15 \%$ sucrose $\left(4{ }^{\circ} \mathrm{C}\right)$. Tissue was embedded (OCT; ProSciTech, Thuringowa, QLD, Australia) and stored at $-80{ }^{\circ} \mathrm{C}$. Coronal sections of the hypothalamus were cut at $40 \mu \mathrm{m}$ thickness on a cryostat (CM3050; Leica, Wetzlar, Germany), and stored in cryoprotective fluid (20\% glycerol, $30 \%$ ethanediol in $0.1 \mathrm{M}$ phosphate buffer at $\mathrm{pH} 7.3$ ) at $-20^{\circ} \mathrm{C}$.

\section{Immunohistochemistry}

Kisspeptin/Fos double-label immunohistochemistry

Anatomically matched single sections representing the rostral, middle, and caudal regions of the ARC approximately $300 \mu \mathrm{m}$ apart were chosen from each ram. Free-floating sections were washed in $0.1 \mathrm{M}$ tris-buffered saline (TBS), and incubated in $1 \%$ sodium borohydride, followed by a blocking serum (0.1 M TBS, $10 \%$ normal goat serum, $0.3 \%$ Triton X-100), and then a rabbit polyclonal antibody raised against Fos protein diluted in a solution of 10\% normal goat serum, $2 \%$ sodium azide and $0.3 \%$ Triton X-100 in TBS (1:500, overnight at room temperature; sc-52, Santa Cruz Biotechnology, Santa Cruz, CA, USA). Fos was visualised with a goat anti-rabbit secondary antibody (1:400, Alexa 488, Invitrogen, San Diego, CA, USA). Sections were again incubated in blocking serum, and then a rabbit polyclonal antibody raised against ovine kisspeptin-10 (1:2000, overnight at room temperature; no. AC566) and was a gift from A. Caraty (Universite Tours, Nouzilly, France) previously validated for use in sheep tissue (Franceschini et al. 2006; Goodman et al. 2007). Kisspeptin was visualized with a goat anti-rabbit secondary antibody (1:400, Alexa 546, Invitrogen, San Diego, CA, USA). Sections were mounted onto SuperFrost slides and left to dry overnight. Sections were stained with Sudan Black (0.3\% in 70\% ethanol, $3 \mathrm{~min})$, washed in TBS and phosphate-buffered saline and then coverslipped with an anti-fade mounting medium (Fluoromount Dako Corp., Carpinteria, CA, USA). Cells immuno-reactive (ir) for kisspeptin, Fos and both kisspeptin and Fos were counted subjectively by an experienced individual blind to the condition of the animal.

$\mathrm{GnRH} /$ Fos double-label immunohistochemistry

A section representing the mid-POA was chosen from each ram. Immunohistochemistry was conducted as above. The mouse monoclonal primary antibody raised against GnRH (1:1000, MAB5456, EMD Millipore Corporation. Temecula, CA, USA) was visualised with a goat anti-mouse secondary antibody (1:400, Alexa 546, Invitrogen, San Diego, CA, USA). Cells immuno-reactive for GnRH, Fos and both GnRH and Fos were counted subjectively by an experienced individual blind to the condition of the animal.

\section{Radioimmunoassay}

Plasma LH was measured in all samples in duplicate by a double-antibody radioimmunoassay (Martin et al. 1980) using ovine LH (NIDDK-oLH-1-4; AFP-8614B) for iodination and standards kindly supplied by A. Parlow, National Hormone and Pituitary Program, National Institute of Diabetes and Digestive and Kidney Diseases, Torrance, CA, USA. The limit of detection was $0.06 \mathrm{ng} / \mathrm{ml}$. Quality control samples $(0.5,1.1$ and $1.9 \mathrm{ng} / \mathrm{mL})$ were used to calculate intra-assay variation $(<10 \%$ for each $)$.

\section{LH pulse analysis}

Pulses of LH secretion were detected with MUNRO, an adaptation of the PULSAR program (Merriam and Wachter 1982), that was developed for the Apple Macintosh computer ('Munro', Zaristow Software, West Morham, Haddington, East Lothian, UK). For the present study, the G parameters were 10, 5, 3, 2, and 1 for G1 to G5, respectively. The Baxter parameters were 0.0126 (B1, the $y$-intercept), 0.0218 ( $\mathrm{B}_{2}$, the $\mathrm{x}$ coefficient), and $0.0058\left(\mathrm{~B}_{3}\right.$, the $\mathrm{x}^{2}$ coefficient). The other parameters of the Munro program were a smoothing window of $60 \mathrm{~min}$, a nadir window of $40 \mathrm{~min}$, a minimal pulse interval of $60 \mathrm{~min}$, and a rise threshold of 4 S.D. 


\section{Statistical analysis}

All statistical analyses were conducted in Genstat 12.1 (Twelfth edition, Lawes Agricultural Trust, Rothamsted Experimental Station, Hertfordshire, UK).

\section{LH analysis}

Mean LH was compared over $8 \mathrm{~h}$ before vs $2 \mathrm{~h}$ and $8 \mathrm{~h}$ after feeding between control vs supplemented animals using a repeated measures ANOVA. Pulse frequency was calculated as the number of pulses per hour (over $8 \mathrm{~h}$ before and after feeding) and the difference in pulse frequency was analysed using a repeated measures ANOVA. The mean pulse amplitude, area and nadir were calculated for each animal before and after feeding, from data generated by the PULSAR program. Some animals did not have an LH pulse prior to feeding, so there was no 'before' data for pulse characteristics in these animals. Therefore, pulse characteristics were analysed in two ways: First, animals without a 'before' pulse were removed from analysis ( $\mathrm{n}=5$ from the supplemented group), and the remaining animals analysed comparing before vs after feeding and control vs supplemented animals (resulting group sizes: control: $\mathrm{n}=3$, supplemented: $\mathrm{n}=4$ ). For pulse nadir, this was done using a repeated measures ANOVA, and day of experimentation was used as a blocking factor. However, data for amplitude and area violated normality and homogeneity of variance assumptions, and so were analysed using a Wilcoxon Matched Pairs tests to compare before vs after feeding, and Mann-Whitney U tests to compare control vs supplemented animals either before or after feeding. These data are presented as the median and $95 \%$ CI or interquartile range.

Second, all animals were analysed comparing control and supplemented animals only after feeding (control: $\mathrm{n}=3$, supplemented: $\mathrm{n}=9$ ). For pulse amplitude and nadir this was done using a one-way ANOVA. Day of experimentation was used as a blocking factor. Prior to analysis pulse amplitude was transformed (logarithm base e) to adhere to normality and homogeneity of variance assumptions.

Pulse area violated normality and homogeneity of variance assumptions, and so was analysed using a Mann-Whitney U test.

Results from each way of testing did not yield conflicting results. Pulse amplitude, area and nadir data presented in the paper is the mean of data from all animals killed $11 \mathrm{~h}$ post-feeding.

Immunohistochemistry data

One animal from the supplemented treatment killed $11 \mathrm{~h}$ after feeding was excluded from analysis of the hypothalamic regions because the hypothalamic sections were damaged during processing and we were unable to obtain meaningful data (resulting group sizes: control $2 \mathrm{~h}: \mathrm{n}=5$, supplemented $2 \mathrm{~h}$ : $\mathrm{n}$ $=7$, control $11 \mathrm{~h}: \mathrm{n}=3$, supplemented $11 \mathrm{~h}: \mathrm{n}=8$ ). The number of kisspeptin neurons in each region of the hypothalamus and the number of GnRH neurons in the POA was analysed using a two-way ANOVA, comparing $2 \mathrm{~h}$ and $11 \mathrm{~h}$ post-feeding and control vs supplemented animals. Day of experimentation was used as a blocking factor. Data for percentage of kisspeptin neurons co-labelling for Fos and percentage of GnRH neurons co-labelling for Fos were unable to be transformed to adhere to normality and homogeneity of variance assumptions, and so were analysed using a Kruskall-Wallis one way ANOVA, comparing collection-time and supplementation separately. Overall activation of neurons as indicated by the presence of Fos was analysed in each region using a two-way ANOVA, comparing before vs after feeding and control vs supplemented animals. Day of experimentation was used as a blocking factor. 


\section{Results}

\section{LH secretion}

Representative LH profiles are shown for control and feed supplemented rams (Figure 1).

Mean LH increased immediately (2 h) following supplementation $(\mathrm{P}<0.05)$, but was unchanged over the full $11 \mathrm{~h}$ post-feeding period (Figure 2A).
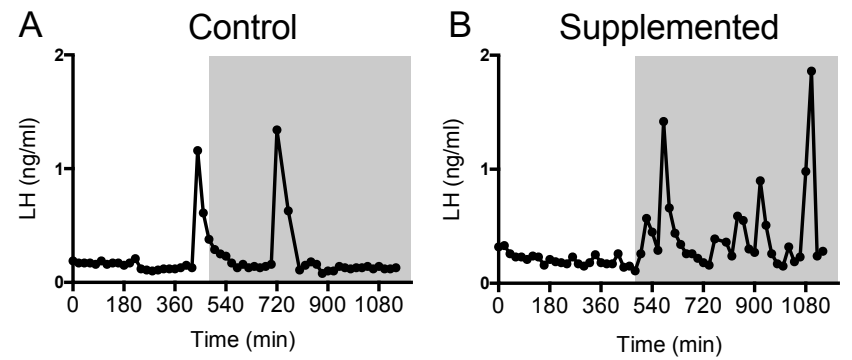

Fig. 1. Plasma LH profiles are shown in representative animals fed either their usual ration (Control) or supplemented with extra lupins. The timing of feeding is indicated by the shaded area. $\mathrm{LH}$ pulses are indicated by arrows.
LH pulse frequency differed with time and supplementation, with a significant interaction $(\mathrm{P}<0.05)$. Specifically, post feeding pulse frequency increased by over 2-fold in supplemented animals compared to control animals $(\mathrm{P}<0.01$; Figure 2B). Pulse amplitude, nadir, and area did not change with time, supplementation, nor was there an interaction between time and supplementation (Table 1).

\section{Presence and activation of kisspeptin and GnRH} neurons

There were more kisspeptin neurons in the caudal ARC of supplemented rams than in control rams $(\mathrm{P}<0.05)$, regardless of time of death (Table 2 and Figure $3 \mathrm{~A}$ and $\mathrm{B}$ ). However, there was no difference in the number of kisspeptin neurons in either the mid or rostral regions of the ARC, nor was there an effect of time of death (Table 2).

There was a higher percentage of kisspeptin neurons co-labelled for Fos in the caudal ARC of supplemented rams than in control rams $(\mathrm{P}<0.05$, Figure $3 \mathrm{C}$ and $\mathrm{D})$; however, there was no difference in the percentage of kisspeptin neurons co-labelled for Fos in either the mid or rostral regions of the ARC (Table 2). There was no difference in the number or activation of GnRH neurons in the POA between supplemented and control rams at 2 and $11 \mathrm{~h}$ post-feeding (Table 2 and Figure $3 \mathrm{E}$ and F).
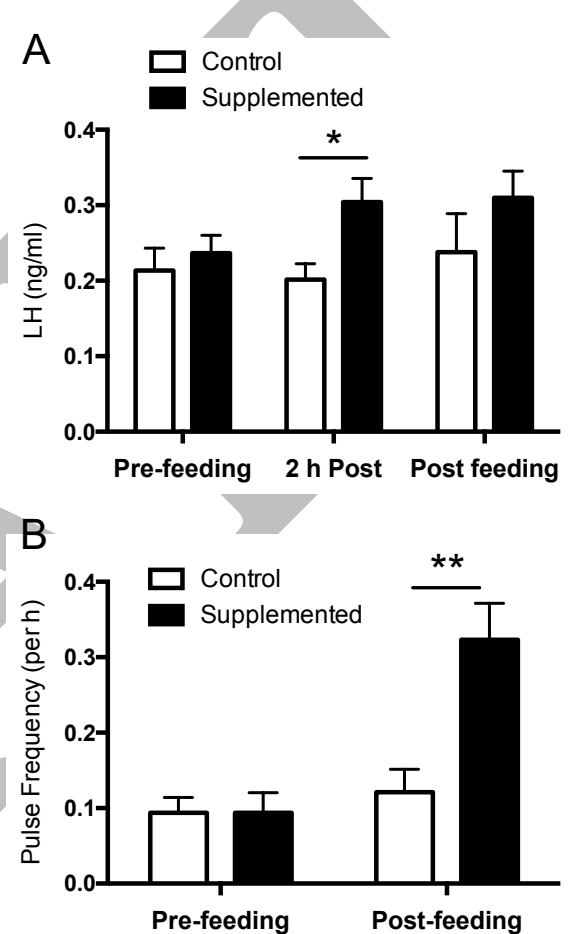

Fig. 2. Mean LH (A) and LH pulse frequency (B) in animals before and after feeding usual rations (Control) or supplemented with extra lupin grain. The pre-feeding and post-feeding periods were $8 \mathrm{~h}$, with an addition $2 \mathrm{~h}$ post feeding group included for mean LH analysis. Group numbers: Pre-feeding and 2 h Post, control $n=8$, supplemented $n=16$; Postfeeding, control $n=3$, supplemented $n=9$. Mean \pm S.E. shown. * indicates $\mathrm{P}<0.05$ compared to control. $* *$ indicates $\mathrm{P}<0.01$ compared to control.

\section{Overall neural activation after lupin supplementation}

There were more neurons labelled for Fos in the mid ARC and mid dorsomedial hypothalamus of the supplemented rams compared to the control rams (both $\mathrm{P}<0.05$; Table 3 , Figure $3 \mathrm{G}$ and $\mathrm{H}$ ). There was no effect of supplementation on Fos activation in the regions of the rostral or caudal ARC or dorsomedial hypothalamus, the paraventricular nucleus or the POA. There was no effect of kill-time nor an interaction between kill-time and supplementation on Fos activation in any region. 
Table 1. LH pulse characteristics in rams fed either their usual ration $(n=3)$ or supplemented with extra lupin grain $(\mathbf{n}=\mathbf{9})$. Mean \pm S.E. shown.

\begin{tabular}{lcccc}
\hline & \multicolumn{2}{c}{ Pre-feeding $(8 \mathrm{~h})$} & \multicolumn{2}{c}{ Post-feeding $(8 \mathrm{~h})$} \\
& Control & Supplemented & Control & Supplemented \\
\hline Amplitude $(\mathrm{ng} / \mathrm{mL})$ & $0.80 \pm 0.11$ & $0.68 \pm 0.30$ & $1.40 \pm 0.72$ & $0.60 \pm 0.09$ \\
Nadir $(\mathrm{ng} / \mathrm{mL})$ & $0.15 \pm 0.04$ & $0.24 \pm 0.07$ & $0.16 \pm 0.03$ & $0.18 \pm 0.02$ \\
Area $(\mathrm{ng} / \mathrm{mL})$ & $50.4 \pm 7.17$ & $40.0 \pm 16.09$ & $56.8 \pm 25.62$ & $26.4 \pm 2.56$ \\
\hline
\end{tabular}

Table 2. Presence and activation of kisspeptin neurons within the ARC and GnRH neurons within the POA in rams fed either their usual ration $(n=8)$ or supplemented with extra lupin grain $(n=15), 2$ or 11 h after feeding. Group numbers: control $2 \mathrm{~h}: \mathrm{n}=5$, control $11 \mathrm{~h}: \mathrm{n}=3$, supplemented $2 \mathrm{~h}: \mathrm{n}=7$, supplemented $11 \mathrm{~h}: \mathrm{n}=7$ for hypothalamic regions, 8 for pre-optic area. Mean \pm S.E. shown. * Indicates $(\mathrm{P}<0.05)$ between control and supplemented animals within that brain region.

\begin{tabular}{llcccc}
\hline & & \multicolumn{2}{c}{$2 \mathrm{~h}$ post-feeding } & \multicolumn{2}{c}{$11 \mathrm{~h}$ post-feeding } \\
& & Control & Supplemented & Control & Supplemented \\
\hline $\begin{array}{l}\text { Number of ARC kisspeptin } \\
\text { neurons }\end{array}$ & Caudal & $2.4 \pm 1.08$ & $7.7 \pm 0.52 *$ & $4.3 \pm 2.85$ & $6.9 \pm 1.51 *$ \\
& Mid & $5.8 \pm 0.73$ & $7.0 \pm 1.99$ & $6.7 \pm 4.41$ & $4.9 \pm 1.22$ \\
& Rostral & $5.6 \pm 1.72$ & $7.6 \pm 2.19$ & $9.3 \pm 3.18$ & $6.0 \pm 2.76$ \\
\% ARC kisspeptin + Fos & Caudal & $0 \pm 0.00$ & $5.0 \pm 2.35 *$ & $0 \pm 0.00$ & $3.9 \pm 1.97 *$ \\
& Mid & $10.0 \pm 6.67$ & $3.1 \pm 2.03$ & $2.2 \pm 2.22$ & $14.4 \pm 7.27$ \\
& Rostral & $4.4 \pm 2.72$ & $11.9 \pm 7.76$ & $8.1 \pm 4.82$ & $8.1 \pm 2.30$ \\
& & & & & \\
Number of GnRH neurons & POA & $2.4 \pm 1.17$ & $3.3 \pm 0.87$ & $3.3 \pm 1.76$ & $1.4 \pm 0.59$ \\
& POA & $3.3 \pm 3.33$ & $9.5 \pm 7.14$ & $5.6 \pm 5.56$ & $13.3 \pm 12.54$ \\
\hline
\end{tabular}

Table 3. Number of neurons staining for Fos in brain regions of rams fed either their usual ration or supplemented with extra lupin grain, 2 or 11 h post-feeding. Mean \pm S.E. shown. Group sizes: control 2 h: $n$ $=5$, control $11 \mathrm{~h}: \mathrm{n}=3$, supplemented $2 \mathrm{~h}: \mathrm{n}=7$, supplemented $11 \mathrm{~h}: \mathrm{n}=7$ for hypothalamic regions, 8 for preoptic area. * Indicates $(\mathrm{P}<0.05)$ between control and supplemented animals within that brain region.

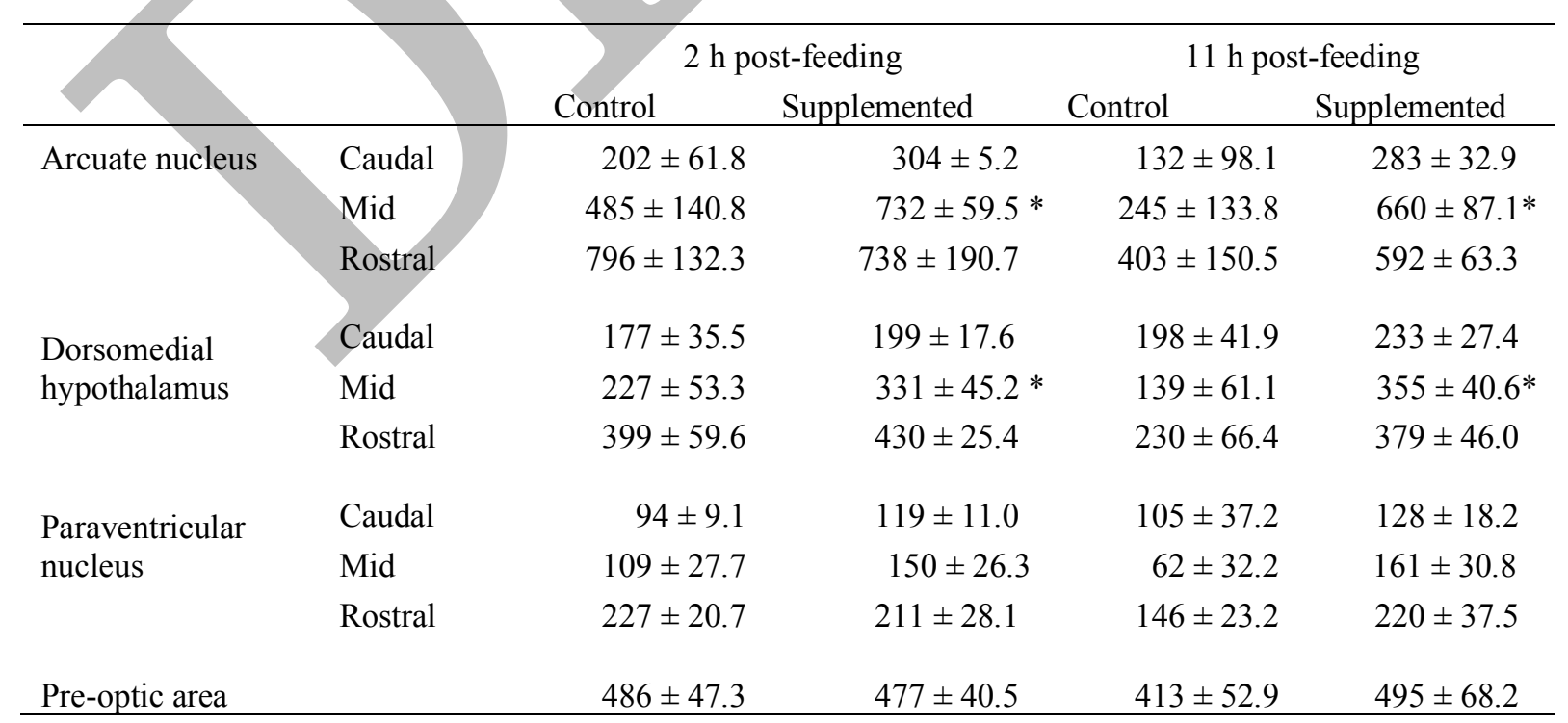



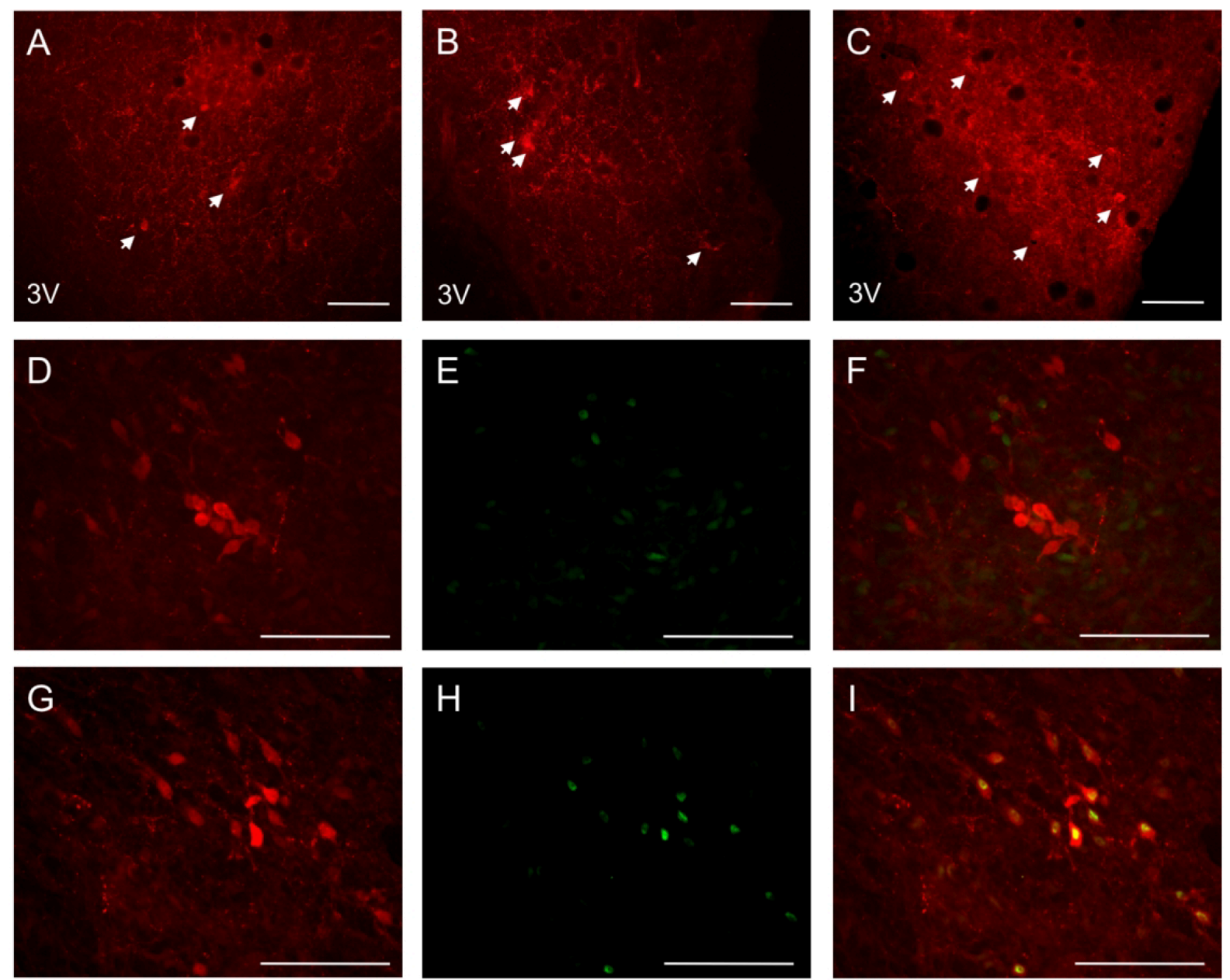

Fig. 3. Representative photomicrographs demonstrating kisspeptin (red) and Fos (green) labelling in rams $2 \mathrm{~h}$ post feeding. A-C: Kisspeptin immunoreactive cells in the arcuate nucleus of a control ram (A) and rams fed lupins (B and C). Arrows indicate positive cells. D-I: Examples of caudal ARC kisspeptin neurons coexpressing Fos in control (D-F) and lupin fed (G-I) rams (note: no co-expression was seen in control). Each panel represents kisspeptin, Fos and the merged image. $3 \mathrm{~V}$, third ventricle. Scale bars, $100 \mu \mathrm{m}$.

\section{Discussion}

In this study, we detected a small but significant increase in LH pulsatility in male sheep immediately following the presentation of a supplemented diet. Paired with this change was a small but significant increase in overall number of kisspeptin neurons in the caudal ARC and the percentage of these kisspeptin neurons co-expressing Fos - indicating activation. We also show neuronal activation of additional hypothalamic neurons in the mid-ARC and dorsomedial hypothalamus. An increase in LH pulses (assumed to be the direct result of GnRH pulses) in sheep in response to supplemented feed was first to demonstrated by Martin and colleagues (Martin et al. 1994). At this time, it was hypothesized that an interplay between nutrition and steroid negative feedback governing GnRH neurons was key to the response (Blache et al. 2006). We now implicate kisspeptin neurons in the caudal ARC in the promulgation of this feeding effect.

Kisspeptin neurons in the ARC are strongly implicated in the generation of GnRH pulses. Data supporting this claim have come from multiple species included mice (Clarkson et al. 2017), goats (Wakabayashi et al. 2010; Wakabayashi et al. 2013) and sheep (Goodman et al. 2013; Li et al. 2015). At its core, the hypothesised GnRH pulse generator relies on the co-expression of NKB and Dyn (and their receptors) in ARC kisspeptin neurons, dubbed the KNDy hypothesis. (Goodman et al. 2007; Navarro et al. 2009; Lehman et al. 2010). The hypothesis stipulates that NKB acts in a reciprocal manner via its receptor on other KNDy neurons to drive pulsatility, Dyn acts as the 'brake' halting 
pulses, and kisspeptin is the final output to GnRH neurons. Although we have not directly visualised or examined NKB or Dyn expression in kisspeptin neurons in our model, the high (almost 100\%) coexpression of NKB and Dyn with ARC kisspeptin neurons (Goodman et al. 2007) does not seem to differ between adult female and male sheep (Cheng et al. 2010). Interestingly, the overall number of KNDy cells appears to be vastly greater in female sheep compared to males (Cheng et al. 2010). This sex difference is consistent with our relatively low numbers of kisspeptin neurons detected per section - similar to that of Cheng et al (Cheng et al. 2010) - and may relate to the additional role of ARC kisspeptin neurons in the female sheep in facilitating the positive feedback induced GnRH surge (Estrada et al. 2006; Smith et al. 2009; Smith et al. 2011). The action of testosterone in rams is also a likely contributor to the low number of kisspeptin neurons detected, with negative feedback actions reducing kisspeptin output in intact rams versus castrated rams (Nestor et al. 2012).
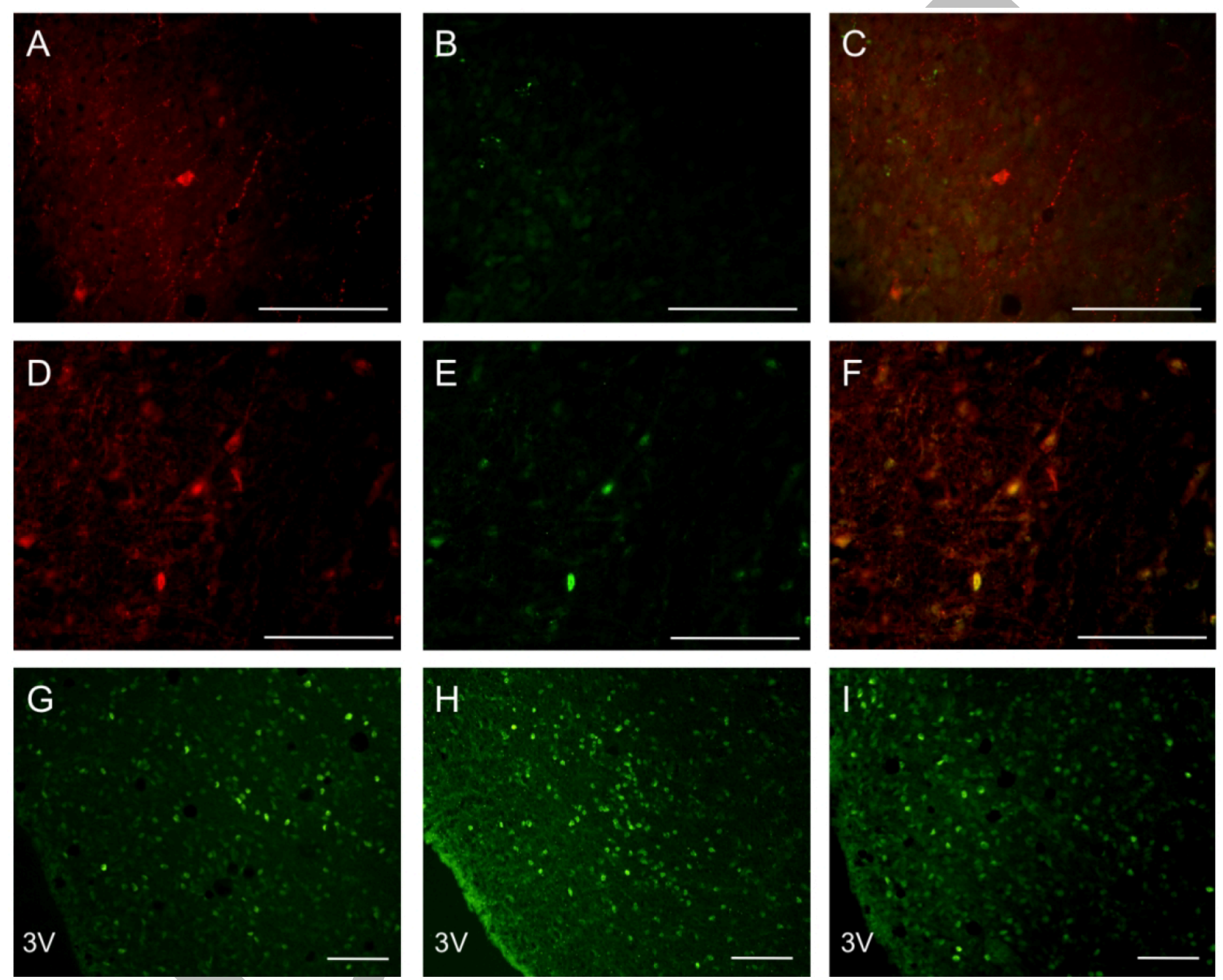

Fig. 4. Representative photomicrographs demonstrating GnRH (red) and Fos (green) 645 labelling in rams $2 \mathrm{~h}$ post feeding. A-F: Examples of preoptic area GnRH neurons co- 646 expressing Fos in control (A-C) and lupin fed (D-F) rams (note: no co-expression was seen in 647 control). G-I: Fos immunoreactive cells in the mid ARC of control animals $(\mathrm{G})$ and animals 648 fed lupins (H and I). 3V, third ventricle. Scale bars, $100 \mu \mathrm{m}$.

Despite our data providing additional support for ARC kisspeptin, or KNDy, neurons facilitating the GnRH induced LH pulses - acting as the pulse generator, recent data have challenged this notion. In sheep, persistent LH pulses are seen in the presence of infused NKB receptor antagonists paired with a constant infusion of kisspeptin (Clarke et al. 2018), indicating KNDy neurons may not be the sole pulse generator in this species. In our study, we noted an overall increase in Fos activation in the mid $\mathrm{ARC}$ associated with increased pulse frequency. This is consistent with published data demonstrating that ARC kisspeptin neurons receive "upstream" input from ARC glutamatergic neurons (Ezzat et al. 2015) - although the majority of KNDy neurons themselves are glutamatergic (Cernea et al. 2015; Merkley et al. 2015) - potentially contributing to the GnRH pulse generator. 
Original studies investigating the supplemented feed effect in male sheep detailed an increase in GnRH pulse frequency within 6 hours of the acute increase in nutrition (Martin et al. 1994; Blache et al. 2003; Zhang et al. 2005; Blache et al. 2006), leading to an increase in testosterone and sperm production (Guan et al. 2017; Guan and Martin 2017). Zhang and colleagues (Zhang et al. 2004; Zhang et al. 2005) showed an increase within 6 hours in males (with a representative male showing a response at 3 hours). Our study showed a response potentially within 2 hours with mean LH significantly greater in supplemented animals at this time. Importantly, supplemented feed effects in male sheep are far more subtle and variable between animals - consistent with our relatively small changes in KNDy neurons - than other stimuli, such as the ram effect (De Bond et al. 2013; FabreNys et al. 2017). This variability is evident in our kisspeptin-fos data, which only represents a single point in time and unfortunately cannot be directed paired to the overall LH activity during each period. Moreover, the neuronal link between hypothalamic-pituitary-gonadal (HPG) activity and nutritional cues is not fully understood. The LH response to supplemented feed is remarkably quick. Moreover, it is associated with no change in POA GnRH neuron number or activation, as determined by Fos immunohistochemistry, consistent with a previous report (Boukhliq et al. 1999). Remarkably, a subpopulation of GnRH neurons, limited to the medial-basal hypothalamus, show activation in rams following introduction to estrous ewes (Boukhliq et al. 1999) raising the possibility that a subset of $\mathrm{GnRH}$ neurons is responsible for GnRH pulses.

The rapid response also begs the question as to what the primary signalling factor from nutrition leads to the change in the hypothalamic KNDy neurons. It most likely involves insulin and leptin, two metabolic hormones that are known to affect reproduction (Blache et al. 2006). Importantly, plasma levels of insulin and leptin increase rapidly following supplemented feed in male sheep - within $3 \mathrm{~h}$ for insulin and there was a transient increase in leptin at $1 \mathrm{~h}$ (Zhang et al. 2004). Both of these hormones have known links to kisspeptin neurons. In mouse models, ARC kisspeptin neurons express the signalling leptin receptor (Smith et al. 2006) and the loss of leptin receptor, as well as insulin receptor signalling in kisspeptin neurons alters the onset of puberty (Qiu et al. 2013; Qiu et al. 2015). In sheep, leptin administration can restore Kiss $1 \mathrm{mRNA}$ expression in the ARC following dietary restriction (Backholer et al. 2010). Alternatively, leptin and insulin could also regulate kisspeptin neurons indirectly in a neuroanatomical pathway involving pro-opiomelanocortin (POMC)/cocaineamphetamine-regulated transcript (CART) and/or neuropeptide Y (NPY)/agouti-related peptide (AGRP) neurons (Backholer et al. 2010; Padilla et al. 2017). An indirect action of leptin on sheep KNDy neurons is also suggested by the absence of leptin-induced phosphor-signal transducer and activator of transcription (pSTAT3) in these cells (Louis et al. 2011). We noted an overall increase in Fos activation in the mid ARC - possibly representing POMC/CART neurons, which are critical for regulation of energy homeostasis, but are also known to project to (Backholer et al. 2010; Cravo et al. 2011) and regulate kisspeptin neurons (True et al. 2013). Consistent with this, we also noted an increase in Fos expression in the dorsomedial hypothalamus (DMH), which is an area critical for leptin regulation of brown adipose tissue (BAT) temperature and the cardiovascular system (Fontes et al. 2001; Marsh et al. 2003; Horiuchi et al. 2006; Enriori et al. 2011; Rezai-Zadeh et al. 2014). Alternatively, other rapid nutrient signals, such a glucose or fatty acids, could signal to KNDy neurons either directly or indirectly and this warrants further investigation.

Overall, we have shown an acute increase in LH pulse frequency in response to nutritional supplementation in male sheep and are the first to implicate caudal ARC kisspeptin (KNDy) neurons (potentially acting as a GnRH pulse generator) in this effect. The results lead to the further understanding of the neuroanatomical pathways in the hypothalamus that mediate the response to feeding and link this to the reproductive system. This may be pertinent to anomalous energy balance links to infertility in humans. We conclude that KNDy neurons in the caudal ARC appear to mediate the increase in $\mathrm{GnRH} / \mathrm{LH}$ production due to nutritional supplementation, further supporting the hypothesised role of the KNDy neurons as the GnRH pulse generator.

\section{Conflicts of Interest}

The authors declare no conflicts of interest. 


\section{Acknowledgements}

This study was supported by the Australian Research Council Discovery Project DP140102495.

\section{References}

Amstalden, M., Coolen, L.M., Hemmerle, A.M., Billings, H.J., Connors, J.M., Goodman, R.L., and Lehman, M.N. (2010) Neurokinin 3 receptor immunoreactivity in the septal region, preoptic area and hypothalamus of the female sheep: colocalisation in neurokinin B cells of the arcuate nucleus but not in gonadotrophinreleasing hormone neurones. J Neuroendocrinol 22(1), 1-12

Backholer, K., Smith, J.T., Rao, A., Pereira, A., Iqbal, J., Ogawa, S., Li, Q., and Clarke, I.J. (2010) Kisspeptin cells in the ewe brain respond to leptin and communicate with neuropeptide $\mathrm{Y}$ and proopiomelanocortin cells. Endocrinology 151(5), 2233-43

Blache, D., Adam, C.L., and Martin, G.B. (2002) The mature male sheep: a model to study the effects of nutrition on the reproductive axis. Reprod Suppl 59, 219-33

Blache, D., Tjondronegoro, S., Blackberry, M.A., Anderson, S.T., Curlewis, J.D., and Martin, G.B. (1997) Gonadotrophin and prolactin secretion in castrated male sheep following subcutaneous or intracranial treatment with testicular hormones. Endocrine 7(2), 235-43

Blache, D., Zhang, S., and Martin, G.B. (2003) Fertility in male sheep: modulators of the acute effects of nutrition on the reproductive axis of male sheep. Reprod Suppl 61, 387-402

Blache, D., Zhang, S., and Martin, G.B. (2006) Dynamic and integrative aspects of the regulation of reproduction by metabolic status in male sheep. Reprod Nutr Dev 46(4), 379-90

Boukhliq, R., Goodman, R.L., Berriman, S.J., Adrian, B., and Lehman, M.N. (1999) A subset of gonadotropinreleasing hormone neurons in the ovine medial basal hypothalamus is activated during increased pulsatile luteinizing hormone secretion. Endocrinology 140(12), 5929-36

Castellano, J.M., Navarro, V.M., Fernandez-Fernandez, R., Nogueiras, R., Tovar, S., Roa, J., Vazquez, M.J., Vigo, E., Casanueva, F.F., Aguilar, E., Pinilla, L., Dieguez, C., and Tena-Sempere, M. (2005) Changes in hypothalamic KiSS-1 system and restoration of pubertal activation of the reproductive axis by kisspeptin in undernutrition. Endocrinology 146(9), 3917-25

Castellano, J.M., Navarro, V.M., Fernandez-Fernandez, R., Roa, J., Vigo, E., Pineda, R., Dieguez, C., Aguilar, E., Pinilla, L., and Tena-Sempere, M. (2006) Expression of hypothalamic KiSS-1 system and rescue of defective gonadotropic responses by kisspeptin in streptozotocin-induced diabetic male rats. Diabetes 55(9), 2602-10

Cernea, M., Padmanabhan, V., Goodman, R.L., Coolen, L.M., and Lehman, M.N. (2015) Prenatal Testosterone Treatment Leads to Changes in the Morphology of KNDy Neurons, Their Inputs, and Projections to GnRH Cells in Female Sheep. Endocrinology 156(9), 3277-91

Cheng, G., Coolen, L.M., Padmanabhan, V., Goodman, R.L., and Lehman, M.N. (2010) The kisspeptin/neurokinin B/dynorphin (KNDy) cell population of the arcuate nucleus: sex differences and effects of prenatal testosterone in sheep. Endocrinology 151(1), 301-11

Clarke, I.J. (2011) Control of GnRH secretion: one step back. Front Neuroendocrinol 32(3), 367-75

Clarke, I.J., Li, Q., Henry, B.A., and Millar, R.P. (2018) Continuous Kisspeptin Restores Luteinizing Hormone Pulsatility Following Cessation by a Neurokinin B Antagonist in Female Sheep. Endocrinology 159(2), 639-646

Clarkson, J., Han, S.Y., Piet, R., McLennan, T., Kane, G.M., Ng, J., Porteous, R.W., Kim, J.S., Colledge, W.H., Iremonger, K.J., and Herbison, A.E. (2017) Definition of the hypothalamic GnRH pulse generator in mice. Proc Natl Acad Sci U S A 114(47), E10216-E10223

Cravo, R.M., Frazao, R., Perello, M., Osborne-Lawrence, S., Williams, K.W., Zigman, J.M., Vianna, C., and Elias, C.F. (2013) Leptin signaling in kiss 1 neurons arises after pubertal development. PLoS One 8(3), e58698

Cravo, R.M., Margatho, L.O., Osborne-Lawrence, S., Donato, J., Atkin, S., Bookout, A.L., Rovinsky, S., Frazao, R., Lee, C.E., Gautron, L., Zigman, J.M., and Elias, C.F. (2011) Characterization of Kiss1 Neurons Using Transgenic Mouse Models. Neuroscience 173, 37-56

De Bond, J.A., Li, Q., Millar, R.P., Clarke, I.J., and Smith, J.T. (2013) Kisspeptin signaling is required for the luteinizing hormone response in anestrous ewes following the introduction of males. PLoS One 8(2), e57972

Enriori, P.J., Sinnayah, P., Simonds, S.E., Garcia Rudaz, C., and Cowley, M.A. (2011) Leptin action in the dorsomedial hypothalamus increases sympathetic tone to brown adipose tissue in spite of systemic leptin resistance. J Neurosci 31(34), 12189-97

Estrada, K.M., Clay, C.M., Pompolo, S., Smith, J.T., and Clarke, I.J. (2006) Elevated KiSS-1 expression in the arcuate nucleus prior to the cyclic preovulatory gonadotrophin-releasing hormone/lutenising hormone 
surge in the ewe suggests a stimulatory role for kisspeptin in oestrogen-positive feedback. $J$ Neuroendocrinol 18(10), 806-9

Ezzat, A., Pereira, A., and Clarke, I.J. (2015) Kisspeptin is a component of the pulse generator for GnRH secretion in female sheep but not the pulse generator. Endocrinology 156(5), 1828-37

Fabre-Nys, C., Cognie, J., Dufourny, L., Ghenim, M., Martinet, S., Lasserre, O., Lomet, D., Millar, R.P., Ohkura, S., and Suetomi, Y. (2017) The Two Populations of Kisspeptin Neurons Are Involved in the RamInduced LH Pulsatile Secretion and LH Surge in Anestrous Ewes. Endocrinology 158(11), 3914-3928

Fontes, M.A., Tagawa, T., Polson, J.W., Cavanagh, S.J., and Dampney, R.A. (2001) Descending pathways mediating cardiovascular response from dorsomedial hypothalamic nucleus. Am J Physiol Heart Circ Physiol 280(6), H2891-901

Franceschini, I., Lomet, D., Cateau, M., Delsol, G., Tillet, Y., and Caraty, A. (2006) Kisspeptin immunoreactive cells of the ovine preoptic area and arcuate nucleus co-express estrogen receptor alpha. Neuroscience Letters 401(3), 225-230

Frazao, R., Dungan Lemko, H.M., da Silva, R.P., Ratra, D.V., Lee, C.E., Williams, K.W., Zigman, J.M., and Elias, C.F. (2014) Estradiol modulates Kiss1 neuronal response to ghrelin. Am J Physiol Endocrinol Metab 306(6), E606-14

Goodman, R.L., Hileman, S.M., Nestor, C.C., Porter, K.L., Connors, J.M., Hardy, S.L., Millar, R.P., Cernea, M., Coolen, L.M., and Lehman, M.N. (2013) Kisspeptin, neurokinin B, and dynorphin act in the arcuate nucleus to control activity of the GnRH pulse generator in ewes. Endocrinology 154(11), 4259-69

Goodman, R.L., Lehman, M.N., Smith, J.T., Coolen, L.M., de Oliveira, C.V., Jafarzadehshirazi, M.R., Pereira, A., Iqbal, J., Caraty, A., Ciofi, P., and Clarke, I.J. (2007) Kisspeptin neurons in the arcuate nucleus of the ewe express both dynorphin A and neurokinin B. Endocrinology 148(12), 5752-60

Guan, Y., Liang, G., Martin, G.B., and Guan, L.L. (2017) Functional changes in mRNA expression and alternative pre-mRNA splicing associated with the effects of nutrition on apoptosis and spermatogenesis in the adult testis. BMC Genomics 18(1), 64

Guan, Y., and Martin, G.B. (2017) Cellular and molecular responses of adult testis to changes in nutrition: novel insights from the sheep model. Reproduction 154(5), R133-R141

Horiuchi, J., McDowall, L.M., and Dampney, R.A. (2006) Differential control of cardiac and sympathetic vasomotor activity from the dorsomedial hypothalamus. Clin Exp Pharmacol Physiol 33(12), 1265-8

Lehman, M.N., Coolen, L.M., and Goodman, R.L. (2010) Minireview: kisspeptin/neurokinin B/dynorphin (KNDy) cells of the arcuate nucleus: a central node in the control of gonadotropin-releasing hormone secretion. Endocrinology 151(8), 3479-89

Li, Q., Millar, R.P., Clarke, I.J., and Smith, J.T. (2015) Evidence that Neurokinin B Controls Basal Gonadotropin-Releasing Hormone Secretion but Is Not Critical for Estrogen-Positive Feedback in Sheep. Neuroendocrinology 101(2), 161-74

Louis, G.W., Greenwald-Yarnell, M., Phillips, R., Coolen, L.M., Lehman, M.N., and Myers, M.G., Jr. (2011) Molecular mapping of the neural pathways linking leptin to the neuroendocrine reproductive axis. Endocrinology 152(6), 2302-10

Marsh, A.J., Fontes, M.A.P., Killinger, S., Pawlak, D.B., Polson, J.W., and Dampney, R.A.L. (2003) Cardiovascular responses evoked by leptin acting on neurons in the ventromedial and dorsomedial hypothalamus. Hypertension 42(4), 488-493

Martin, G.B., Oldham, C.M., and Lindsay, D.R. (1980) Increased Plasma-Lh Levels in Seasonally Anovular Merino Ewes Following the Introduction of Rams. Animal Reproduction Science 3(2), 125-132

Martin, G.B., Tjondronegoro, S., and Blackberry, M.A. (1994) Effects of nutrition on testicular size and the concentrations of gonadotrophins, testosterone and inhibin in plasma of mature male sheep. $J$ Reprod Fertil 101(1), 121-8

Merkley, C.M., Coolen, L.M., Goodman, R.L., and Lehman, M.N. (2015) Evidence for Changes in Numbers of Synaptic Inputs onto KNDy and GnRH Neurones during the Preovulatory LH Surge in the Ewe. $J$ Neuroendocrinol 27(7), 624-35

Merriam, G.R., and Wachter, K.W. (1982) Algorithms for the study of episodic hormone secretion. Am J Physiol 243(4), E310-8

Messager, S., Chatzidaki, E.E., Ma, D., Hendrick, A.G., Zahn, D., Dixon, J., Thresher, R.R., Malinge, I., Lomet, D., Carlton, M.B., Colledge, W.H., Caraty, A., and Aparicio, S.A. (2005) Kisspeptin directly stimulates gonadotropin-releasing hormone release via G protein-coupled receptor 54. Proc Natl Acad Sci U S A 102(5), 1761-6

Navarro, V.M., Gottsch, M.L., Chavkin, C., Okamura, H., Clifton, D.K., and Steiner, R.A. (2009) Regulation of gonadotropin-releasing hormone secretion by kisspeptin/dynorphin/neurokinin B neurons in the arcuate nucleus of the mouse. J Neurosci 29(38), 11859-66

Nestor, C.C., Briscoe, A.M., Davis, S.M., Valent, M., Goodman, R.L., and Hileman, S.M. (2012) Evidence of a role for kisspeptin and neurokinin B in puberty of female sheep. Endocrinology 153(6), 2756-65 
Padilla, S.L., Qiu, J., Nestor, C.C., Zhang, C., Smith, A.W., Whiddon, B.B., Ronnekleiv, O.K., Kelly, M.J., and Palmiter, R.D. (2017) AgRP to Kiss 1 neuron signaling links nutritional state and fertility. Proc Natl Acad Sci U S A 114(9), 2413-2418

Qiu, J., Fang, Y., Bosch, M.A., Ronnekleiv, O.K., and Kelly, M.J. (2011) Guinea pig kisspeptin neurons are depolarized by leptin via activation of TRPC channels. Endocrinology 152(4), 1503-14

Qiu, X., Dao, H., Wang, M., Heston, A., Garcia, K.M., Sangal, A., Dowling, A.R., Faulkner, L.D., Molitor, S.C., Elias, C.F., and Hill, J.W. (2015) Insulin and Leptin Signaling Interact in the Mouse Kiss 1 Neuron during the Peripubertal Period. PLoS One 10(5), e0121974

Qiu, X., Dowling, A.R., Marino, J.S., Faulkner, L.D., Bryant, B., Bruning, J.C., Elias, C.F., and Hill, J.W. (2013) Delayed puberty but normal fertility in mice with selective deletion of insulin receptors from Kiss1 cells. Endocrinology 154(3), 1337-48

Rezai-Zadeh, K., Yu, S., Jiang, Y., Laque, A., Schwartzenburg, C., Morrison, C.D., Derbenev, A.V., Zsombok, A., and Munzberg, H. (2014) Leptin receptor neurons in the dorsomedial hypothalamus are key regulators of energy expenditure and body weight, but not food intake. Mol Metab 3(7), 681-93

Roseweir, A.K., Kauffman, A.S., Smith, J.T., Guerriero, K.A., Morgan, K., Pielecka-Fortuna, J., Pineda, R., Gottsch, M.L., Tena-Sempere, M., Moenter, S.M., Terasawa, E., Clarke, I.J., Steiner, R.A., and Millar, R.P. (2009) Discovery of potent kisspeptin antagonists delineate physiological mechanisms of gonadotropin regulation. J Neurosci 29(12), 3920-3929.

Smith, J.T., Acohido, B.V., Clifton, D.K., and Steiner, R.A. (2006) KiSS-1 neurones are direct targets for leptin in the ob/ob mouse. J Neuroendocrinol 18(4), 298-303

Smith, J.T., and Clarke, I.J. (2007) Kisspeptin expression in the brain: catalyst for the initiation of puberty. Rev Endocr Metab Disord 8(1), 1-9

Smith, J.T., Li, Q., Pereira, A., and Clarke, I.J. (2009) Kisspeptin neurons in the ovine arcuate nucleus and preoptic area are involved in the preovulatory luteinizing hormone surge. Endocrinology 150(12), 5530-8

Smith, J.T., Li, Q., Yap, K.S., Shahab, M., Roseweir, A.K., Millar, R.P., and Clarke, I.J. (2011) Kisspeptin is essential for the full preovulatory $\mathrm{LH}$ surge and stimulates $\mathrm{GnRH}$ release from the isolated ovine median eminence. Endocrinology 152(3), 1001-12

Tjondronegoro, S., Martin, G.B., Sutherland, S.R., and Boukhliq, R. (1996) Interactions between nutrition, testosterone and inhibin in the control of gonadotrophin secretion in mature rams. Reprod Fertil Dev 8(5), 855-62

Tolson, K.P., Garcia, C., Yen, S., Simonds, S., Stefanidis, A., Lawrence, A., Smith, J.T., and Kauffman, A.S. (2014) Impaired kisspeptin signaling decreases metabolism and promotes glucose intolerance and obesity. J Clin Invest 124(7), 3075-9

True, C., Verma, S., Grove, K.L., and Smith, M.S. (2013) Cocaine- and amphetamine-regulated transcript is a potent stimulator of $\mathrm{GnRH}$ and kisspeptin cells and may contribute to negative energy balance-induced reproductive inhibition in females. Endocrinology 154(8), 2821-32

Wakabayashi, Y., Nakada, T., Murata, K., Ohkura, S., Mogi, K., Navarro, V.M., Clifton, D.K., Mori, Y., Tsukamura, H., Maeda, K., Steiner, R.A., and Okamura, H. (2010) Neurokinin B and dynorphin a in kisspeptin neurons of the arcuate nucleus participate in generation of periodic oscillation of neural activity driving pulsatile gonadotropin-releasing hormone secretion in the goat. J Neurosci 30(8), 3124-32

Wakabayashi, Y., Yamamura, T., Sakamoto, K., Mori, Y., and Okamura, H. (2013) Electrophysiological and morphological evidence for synchronized GnRH pulse generator activity among Kisspeptin/neurokinin B/dynorphin A (KNDy) neurons in goats. J Reprod Dev 59(1), 40-8

Weems, P.W., Witty, C.F., Amstalden, M., Coolen, L.M., Goodman, R.L., and Lehman, M.N. (2016) kappaOpioid Receptor Is Colocalized in GnRH and KNDy Cells in the Female Ovine and Rat Brain. Endocrinology 157(6), 2367-79

Zhang, S., Blache, D., Blackberry, M.A., and Martin, G.B. (2004) Dynamics of the responses in secretion of luteinising hormone, leptin and insulin following an acute increase in nutrition in mature male sheep. Reprod Fertil Dev 16(8), 823-9

Zhang, S., Blache, D., Blackberry, M.A., and Martin, G.B. (2005) Body reserves affect the reproductive endocrine responses to an acute change in nutrition in mature male sheep. Anim Reprod Sci 88(3-4), 25769 